\title{
Finite Element Simulation of Thermal Field in Double Wire Welding
}

\author{
Xiuzhi Yang, Chunjie Yang, Chunfa Dong, Xinhua Xiao, Wenlin Hua, Xiangjie Wang \\ Hubei Polytechnic University, Huangshi, China \\ Email: yangliushuzhi@163.com
}

How to cite this paper: Yang, X.Z., Yang, C.J., Dong, C.F., Xiao, X.H., Hua, W.L. and Wang, X.J. (2016) Finite Element Simulation of Thermal Field in Double Wire Welding. Journal of Materials Science and Chemical Engineering, 4, 10-21. http://dx.doi.org/10.4236/msce.2016.412002

Received: October 25, 2016 Accepted: November 25, 2016 Published: December 1, 2016

\begin{abstract}
In this paper, the thermal field of double wire welding is simulated by using ANSYS software. Simulation results were shown that the total heat input (E) is the most significant parameters to change the value of $\mathrm{t}_{8 / 5}$; By the mean of rationally controlling the proportion of the front arc heat input (E1) in the total heat input (E) and appropriately selecting double wire spacing (L), It is effective means to get the double wire welding thermal cycle. By the way of simulation, it is possible to manage the thermal input in the double welding wires and to control the temperature field and cooling rate that are fundamental for the final joint quality, it is great importance guidance to optimize the double wire welding process parameters.
\end{abstract}

\section{Keywords}

Temperature Field, Double Wire Welding, Numerical Simulation, Characteristic Parameter of Thermal Cycling

\section{Introduction}

Welding thermal cycle is a dynamic thermal process, which involves arc physical, material, metallurgy and chemical change, heat transfer, mass transfer and the mechanical property variation. During the welding process and after welding, because of the welding residual stress and distortion, welding thermal affects the manufacturing precision of welding structure, strength, toughness and operational performance. The practical significance of welding the three dimensional numerical simulation lies in the fact that comprehensive prediction weld defects, analysis of laws of welding residual stress and deformation, to optimize the welding structure and process, control of welding stress and deformation [1] [2] [3] [4]. Welding numerical simulation technology has become an important development direction and technical means at home and abroad. 
Welding thermal process directly determine the microstructure and mechanical properties of welded joint. There are four principal parameters in welding thermal cycle as following: The welding speed $(v)$ which influence the austenitic homogenization and microstructure; the heating the highest temperature (Tp) which determine metal phase change and austenitized after welding; the cooling welding rate $\left(t_{8 / 5}, t_{8 / 3}\right)$ affect the joint process of phase transformation; And cooling time of temperature from $400^{\circ} \mathrm{C}$ to $150^{\circ} \mathrm{C}$ is for the spread of the hydrogen cold cracks. So it is very necessary to optimize parameters of the welding thermal cycle to study the influence of welding thermal process on the microstructure and mechanical properties, to control phase transformation of HAZ (heat affected zone), stress, and strain of welded joint [5] [6] [7]. By the way of numerical simulation of transient temperature field and welding strain field, it can provide a reference to eliminate the welding stress and defects for practical welding.

\section{Experimental Set up}

\subsection{Material of Test Steel}

The tests welding plate materials is $10 \mathrm{Ni} 3 \mathrm{CrMoV}$ steel, Its chemical components are shown in Table 1.

\subsection{Numerical Model}

According to symmetry of the simulation calculation of geometric objects and the applied load, the simulation calculation of geometric model and finite element model are half, and the model is divided into three areas: far away from the weld zone (base zone), transition zone (fusion zone) and weld zone, for greatly reduce the number of units in the finite element calculation process.

In this paper, the size of simplified half geometric model is $500 \mathrm{~mm} \times 75 \mathrm{~mm} \times 16$ $\mathrm{mm}$, as shown in Figure 1. In thermal simulation, three-dimensional thermal entity unit SOLID70 and units SOLID90 in ANSYS software were chosen, in weld area, in order to convenient unit selection and heat load applied next, the unit mesh grid hexahedron was selected. The meshed finite element model is shown in Figure 2. In numerically simulate, the values of thermal physical parameters change with temperature, The interpolation method was used to determine the values of thermal physical property parameters at high temperature, the part of the curves in thermal and physical properties are shown in Figure 3 and Figure 4. The boundary conditions are established as following: the room temperature is $30^{\circ} \mathrm{C}$, in order to prevent the rigid displacement, the corresponding displacement constraints of the steel plate was imposed along the weld line, the model of respectively applied convective heat transfer boundary

Table 1. The chemical components of $10 \mathrm{Ni} 3 \mathrm{CrMoV}$ test steel (W/\%).

\begin{tabular}{|c|c|c|c|c|c|c|c|c|}
\hline Elements & $\mathrm{C}$ & $\mathrm{Si}$ & Mn & $\mathrm{Cr}$ & $\mathbf{P}$ & $S$ & $\begin{array}{c}\text { Section } \\
\text { shrinkage/\% }\end{array}$ & Elongation/\% \\
\hline Percent & $0.796-0.834$ & $0.195-0.305$ & $0.7-0.8$ & $0.14-0.22$ & $<0.015$ & $<0.005$ & $>30$ & $>10$ \\
\hline
\end{tabular}




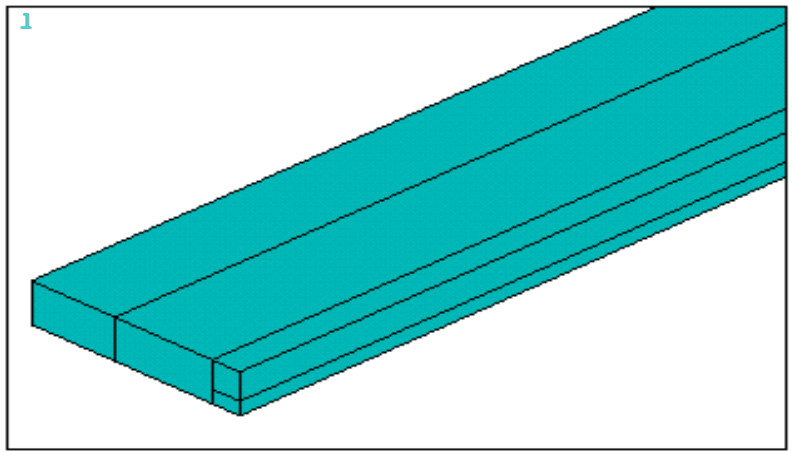

Figure 1. Geometric model.

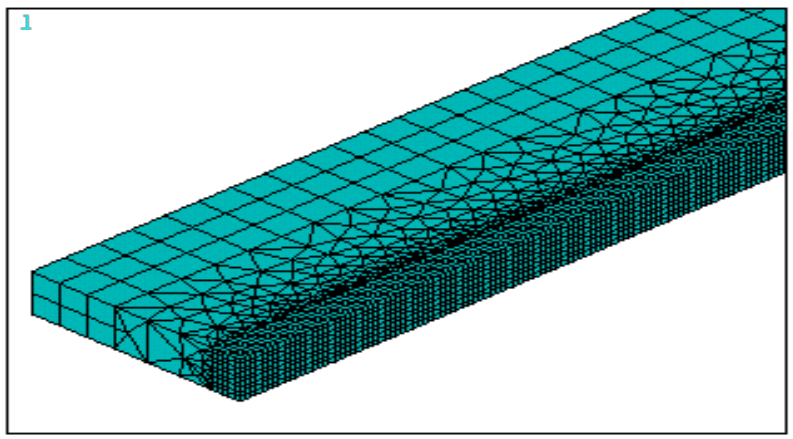

Figure 2. Finite element mesh model.

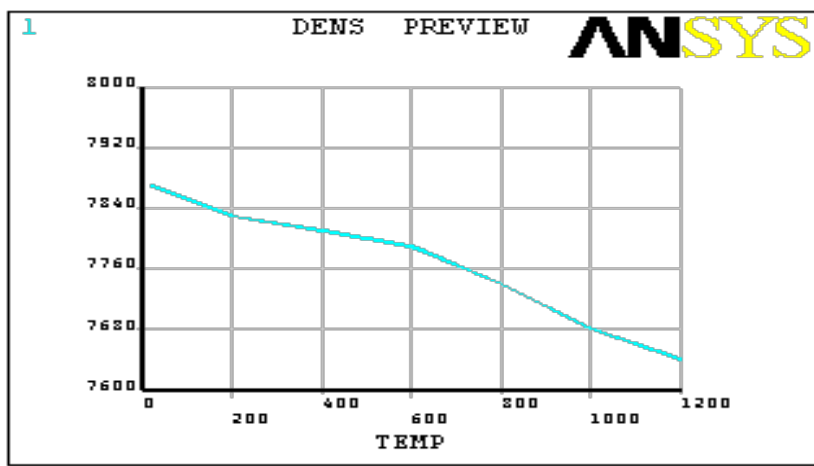

Figure 3. Density changing curve with temperature.

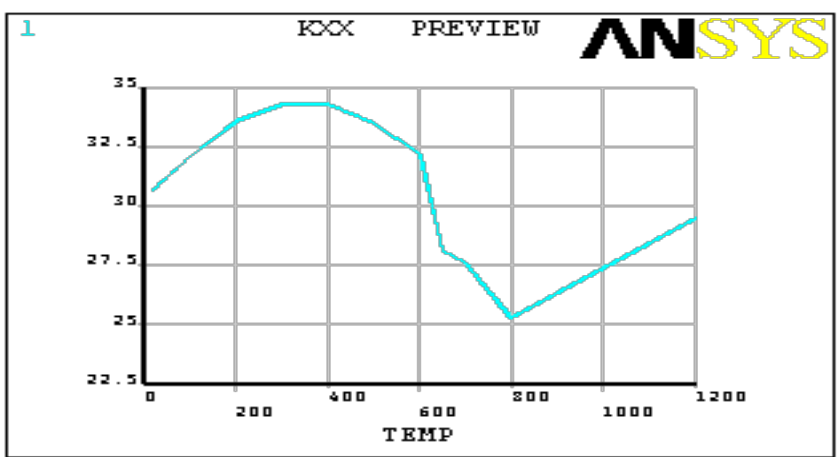

Figure 4. Heat conduction coefficient curve with temperature. 
and displacement constraints on finite element model are shown in Figure 5 and Figure 6.

\subsection{The Heat Source Model}

Double ellipsoid heat source model is more suitable for the simulation of fusion welding process with the characteristic of width and deep welding pool [3] [8]. So in this article, the penetration type double ellipsoid heat source model was chosen to numerical calculation temperature field of double wire welding. The mathematic model of internal heat source is shown in Figure 7, the energy distribution coefficient of the before and after half of ellipsoid set are $f_{f}$ and $f_{r}$ respectively, and the $f_{f}+f_{r}=2$. Heat flux distribution function is following Formulas (1) and (2).

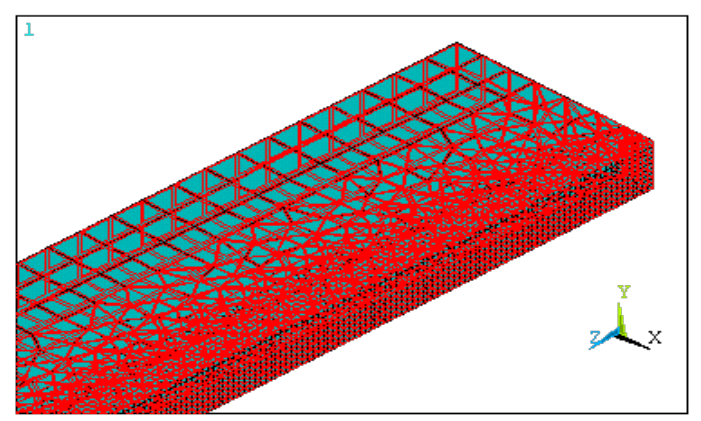

Figure 5. Surface convection boundary model.

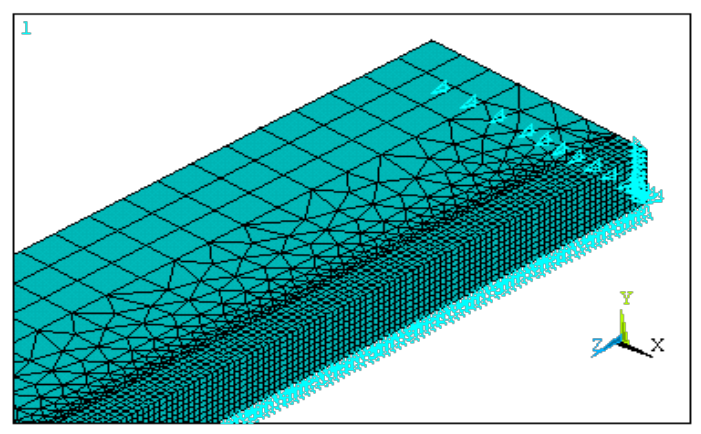

Figure 6. Displacement constraints model.

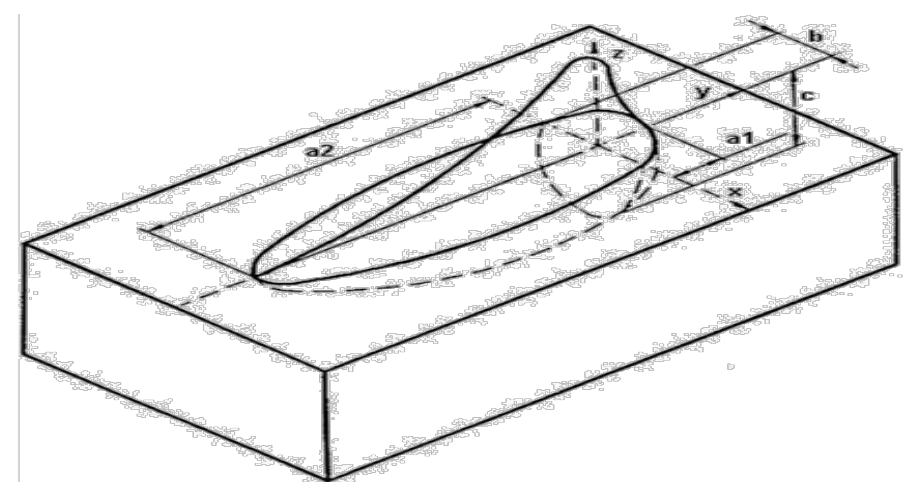

Figure 7. Double ellipsoid heat source model. 


$$
\begin{aligned}
& q_{f i}(x, y, z, t)=\frac{6 \sqrt{3} f_{f} Q_{i}}{a_{i 1} b_{i} c_{i} \pi \sqrt{\pi}} \exp \left(-\frac{3 x^{2}}{a_{i 1}^{2}}\right) \exp \left(-\frac{3 y^{2}}{b_{i}^{2}}\right) \exp \left(-\frac{3 z^{2}}{c_{i}^{2}}\right) \\
& q_{r i}(x, y, z, t)=\frac{6 \sqrt{3} f_{r} Q_{i}}{a_{i 2} b_{i} c_{i} \pi \sqrt{\pi}} \exp \left(-\frac{3 x^{2}}{a_{i 2}^{2}}\right) \exp \left(-\frac{3 y^{2}}{b_{i}^{2}}\right) \exp \left(-\frac{3 z^{2}}{c_{i}^{2}}\right)
\end{aligned}
$$

Among them, the characteristic parameters such as $a_{i j}, b_{i}, c_{i}(i=1,2 ; j=1,2)$ are related to the shape of molten pool, desirable different values and independent of each other, by the adjusting of a, b, c parameters, we can adjust the temperature field simulation. The arc energy distribution coefficient of the front $\left(f_{f}\right)$ and rear $\left(f_{r}\right)$ were $f_{f}=0.48$, $\mathrm{f}_{\mathrm{r}}=1.52$.

\subsection{Numerical Simulation Specification of Double Wire Welding}

Because of the effect of moving welding heat source, the temperature of spot in the workpiece changing with time, called the point of welding thermal cycle. Influence of welding thermal cycle curve parameters mainly includes electric arc voltage $(U)$, as well as double wire welding current(I), welding speed $(v)$, distance $(\mathrm{L})$ between the two wires. And heat flow calculation and load the program were designed and published in my literatures [1] and [2].

The total heat input $\mathrm{E}(\mathrm{KJ} / \mathrm{cm})$ of double wire submerged arc welding calculation expression is: $\mathrm{E}=\eta\left(\mathrm{U}_{1} \mathrm{I}_{1}+\mathrm{U}_{2} \mathrm{I}_{2}\right) / v$, to the double wire submerged arc welding $(\eta)$, it is taken above 0.8 [3] [8]. The fluctuations of voltage $\mathrm{U}$ is from negative $5 \mathrm{~V}$ to positive $5 \mathrm{~V}$, current amplitude is from plus to minus $10 \mathrm{~A}$, the welding speed was taken 60,80 and $100 \mathrm{~cm} / \mathrm{min}$. According to the different combinations of $U_{1}, I_{1}$, and $U_{2}, I_{2}$ and $v$, the $\mathrm{E}_{1}, \mathrm{E}_{2}$ and $\mathrm{E}$ can be taken different values, as shown in Figure 8. From the diagram, different welding parameters can get 21 sets of $E$ values, the biggest $E$ value is $52.33 \mathrm{KJ} / \mathrm{cm}$,

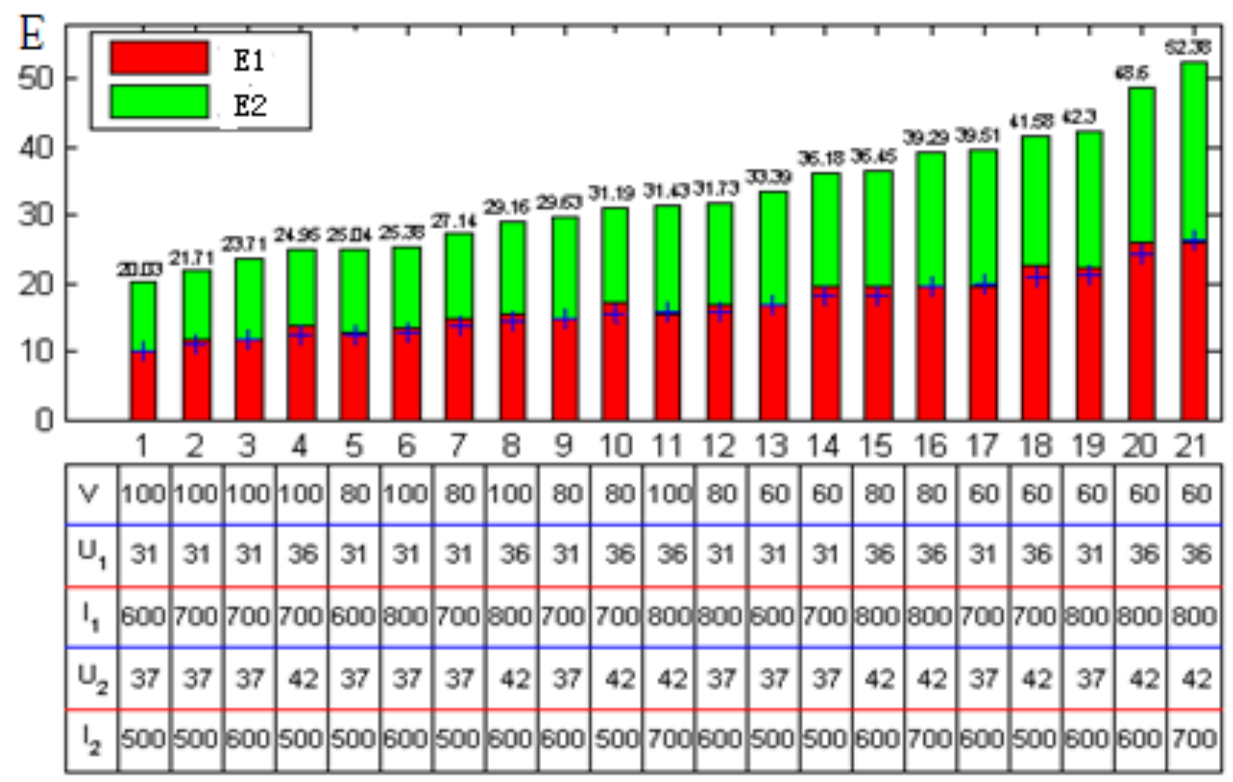

Figure 8. Welding heat input and welding parameters. 
the smallest $\mathrm{E}$ value of $20.03 \mathrm{KJ} / \mathrm{cm}$; And, the heat input value of frontal $\operatorname{arc}\left(E_{1}\right)$ and back $\operatorname{arc}\left(E_{2}\right)$ are different, The length of red, green histogram are respectively shown the value of the heat input of before and after the arc. The position of blue plus sign is shown the average value of E, when it landed in the red areas indicating E1 $>$ E2, fell on the green area indicating the $\mathrm{E}_{1}<\mathrm{E}_{2}$. Therefore, based on the 21 sets of different welding parameters and double wire spacing, the welding temperature field is simulated, and the relationship of the heat input $\mathrm{E}$ and double wire spacing $\mathrm{L}$ with the thermal cycle characteristic parameters were analyzed. Also, the double wire distance L affects the overall welding energy distribution.

\section{Numerical Simulation Results}

\subsection{The Test Results Compared with the Simulation Results}

In simulation and test, the model size is the same of $500 \times 75 \times 16(\mathrm{~mm})$, the welding parameters ( $\mathrm{L}$ is constant $60 \mathrm{~cm}$ ) is been chosen as shown in Figure 8, the simulation is validated by experimentation and the direct measurement of the temperature field with thermocouples, the layout of thermocouples in test is shown in Figure 9. As a result, the test result is shown in Figure 10(a), the molten pool is formed as shown in Figure 11 (take higher than $1500^{\circ} \mathrm{C}$ area as molten pool section) in the simulation, both of them are independent molten pool in the simulation and test, and the size error is within $5 \%$.

\subsection{Location Selection in Result Analysis}

According to the actual welding seam size and the finite element model, in order to convenient analyses, the taken points in finite element nodes are shown in Figure 11. As shown in Figure 12, the points $\mathrm{O}$ is located weld center line, the $\mathrm{x}$ axis is shown along the width of the weld, the y axis is shown along symmetry plane in the penetration weld seam. By the analysis of the representative points of the thermal cycle, it can get the laws of the double wire welding thermal cycle.
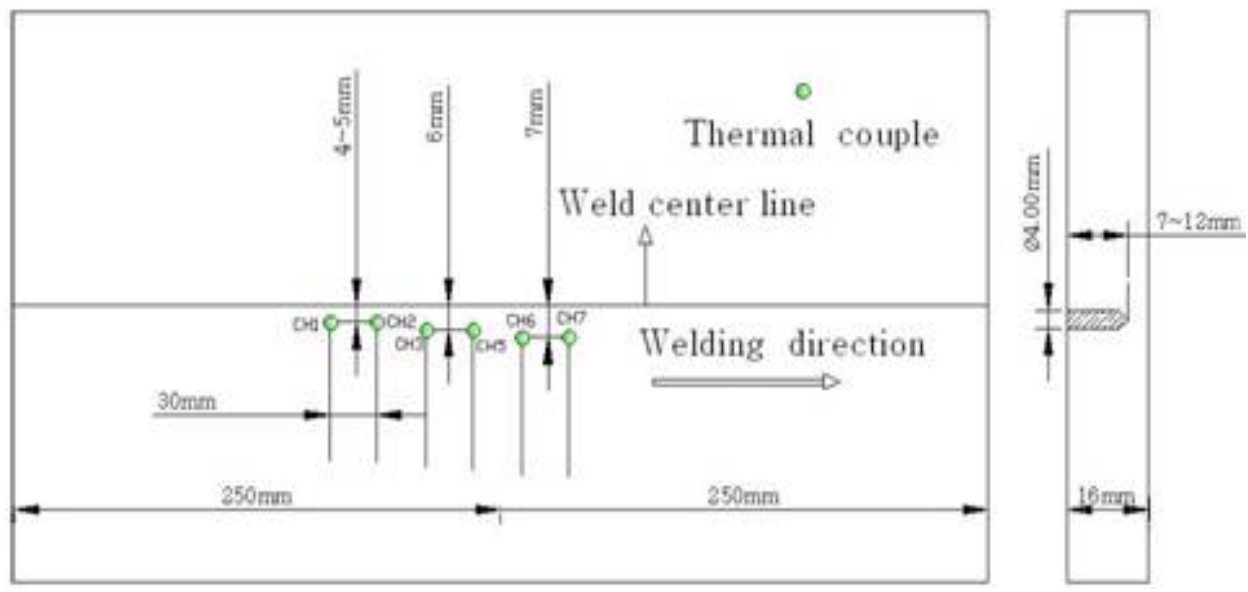

Figure 9. Thermocouple layout in test. 


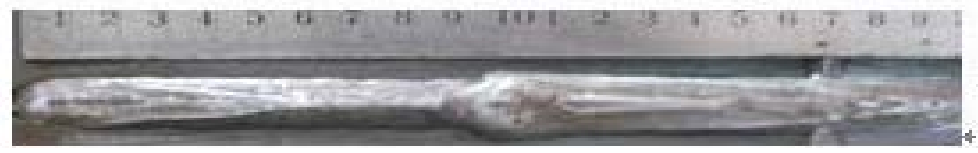

(a)

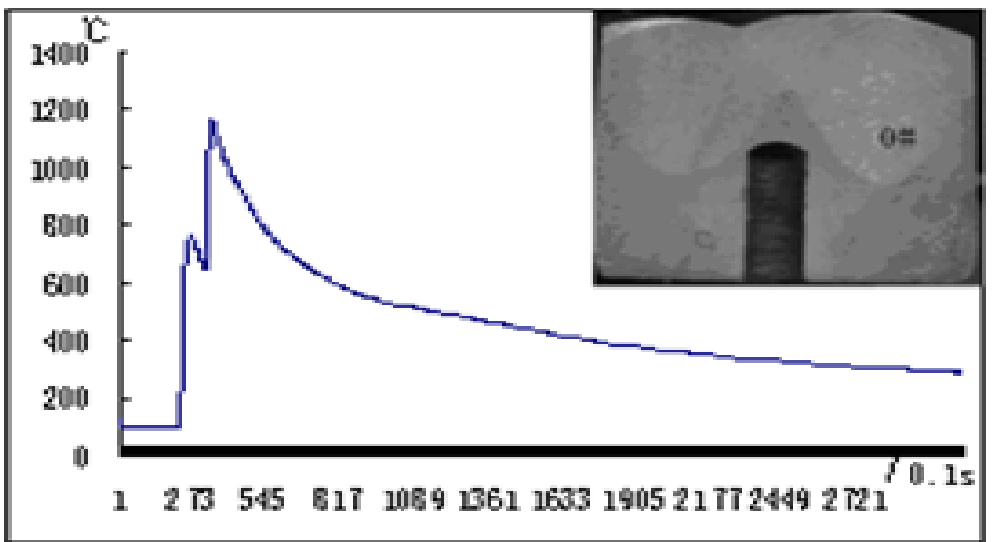

(b)

Figure 10. The measured molten pool and the thermal cycle. (a) Molten pool; (b) The welded joint and the thermal cycle.

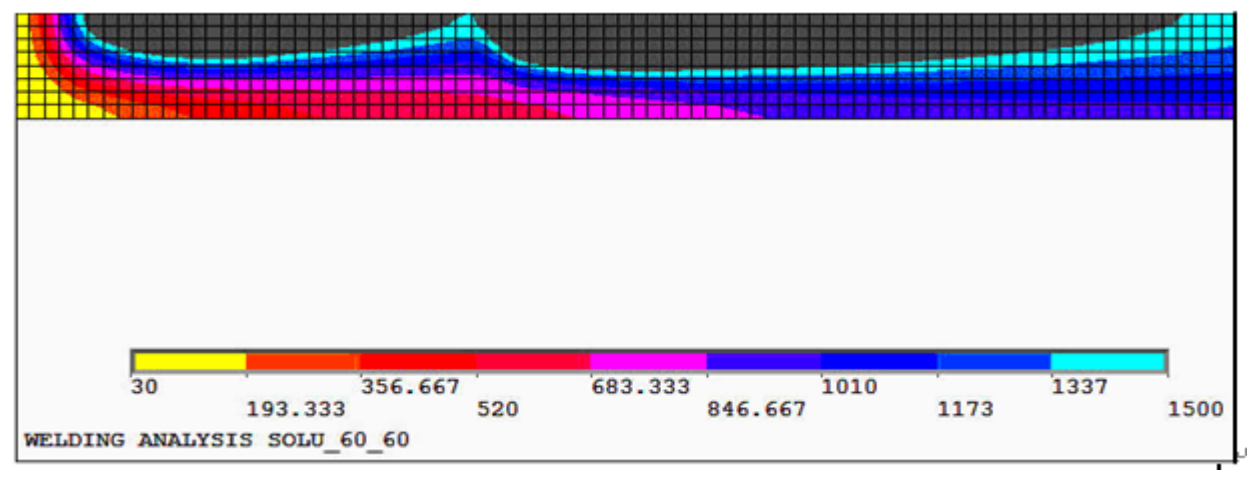

Figure 11. Molten pool topography of $\mathrm{L}=60 \mathrm{~mm}$.

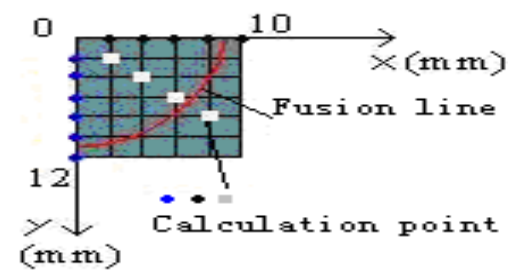

Figure 12. The selected point of weld cross-section.

\section{Analysis of Numerical Simulation}

For different double wire spacing $\mathrm{L}$ and different heat input E, points in different positions have different thermal cycle curve, organization transformation is closely related to the cooling rate. According the double wire welding specification shown in Figure 8, every kinds of temperature fields are calculated by numerical simulation, such as ac- 
cording the specification 2 in Figure 8 at wire spacing $\mathrm{L}=60$ and $100(\mathrm{~mm})$ the simulation of welding temperature field are shown in Figure 13. The correctness of the calculation are examined by the measured values of special point by using thermocouple, such as shown in Figure 14, for the error in 5\%, the simulation results is effective.

\subsection{The $\mathrm{t}_{8 / 5}$ at Same Wire Spacing}

In order to study the effect of heat input $\mathrm{E}$ on $\mathrm{t}_{8 / 5}$ and $\mathrm{Tp}$, The values $(\mathrm{L}=60 \mathrm{~mm})$ of $\mathrm{t}_{8 / 5}$ and $\mathrm{Tp}$ of each special points along penetration direction were statistics, shown in Figure 15 and Figure 16. From Figure 15, we can see that $t_{8 / 5}$ is significant positive correlation with heat input $\mathrm{E}$, and with the increase of heat input $\mathrm{E}$ the values of $\mathrm{t}_{8 / 5}$ are closer. From Figure 16, with the heat input increased, Tp increase too, but the correlation is not obvious.

\subsection{The Tp along Depth and Width of Molten Pool}

With different heat input $\mathrm{E}$ and different double wire spacing $\mathrm{L}$, how about the law of the peak temperature (Tp)? Peak temperature (Tp) of butt welding plate is unfavorable to the microstructure. The following analysis mainly is to find out law of $\mathrm{Tp}$.

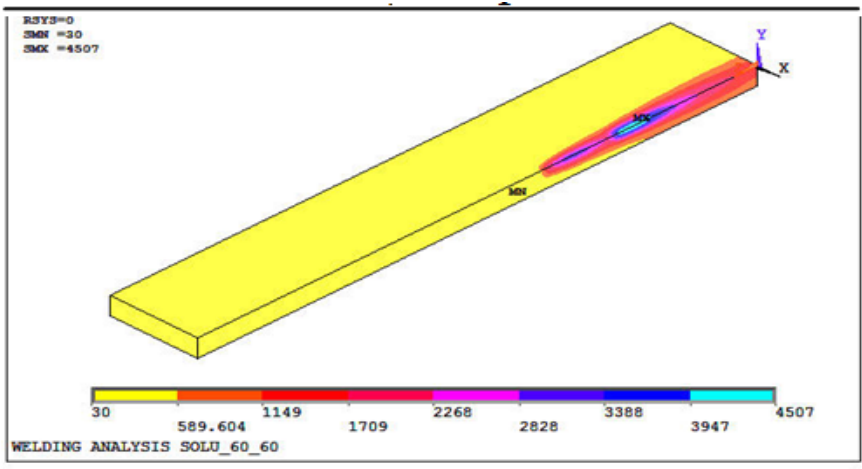

(a)

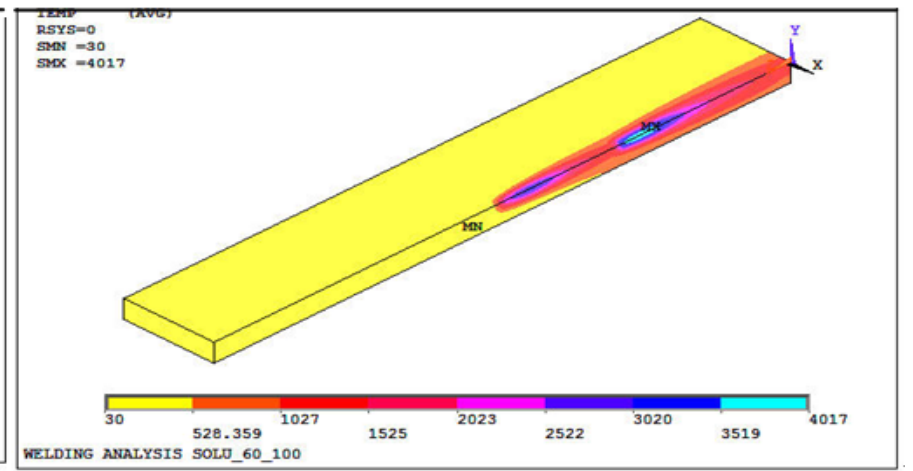

(b)

Figure 13. Double wire welding temperature field. (a) Temperature field ( $\mathrm{L}=60 \mathrm{~mm})$; (b) Temperature field ( $\mathrm{L}=100 \mathrm{~mm})$.

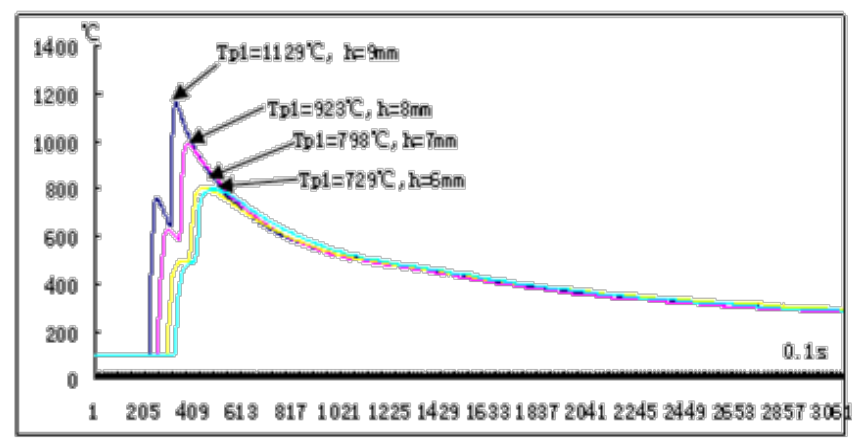

(a)

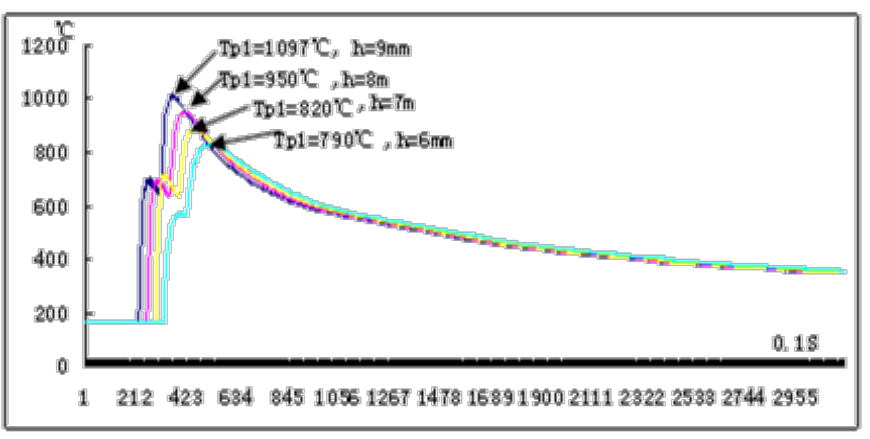

(b)

Figure 14. The thermal cycle curves of points from $(2,6,7)$ to $(2,6,9)$. (a) for the numerical simulation results; (b) for the measured thermal cycle curve, $\mathrm{L}=60 \mathrm{~mm}$ ). 


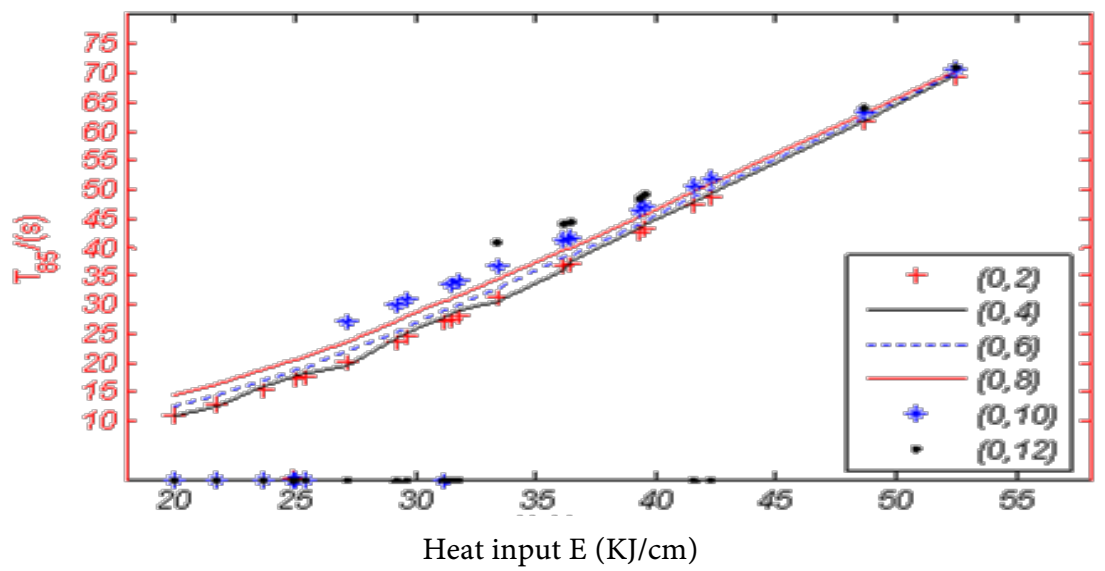

Figure 15. Variation trend of $\mathrm{t}_{8 / 5}$ to heat input $\mathrm{E}$.

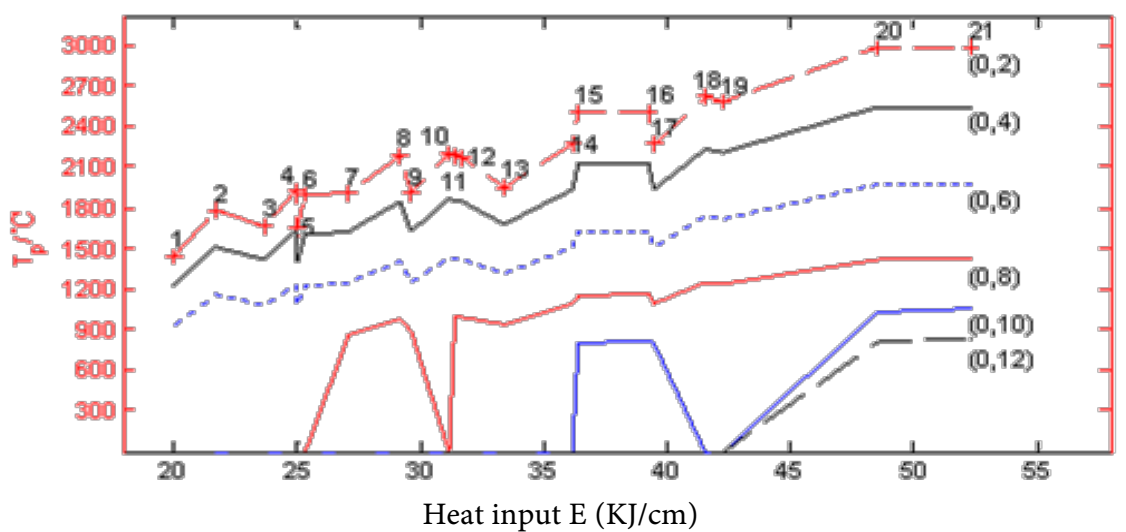

Figure 16. Variation trend of $\mathrm{Tp}$ to heat input $\mathrm{E}$.

\subsubsection{The Tp under Different Double Wire Spacing $L$}

Selected the welding process parameters 2 in Figure 8, under the five different double wire spacing $(60,70,80,90,80 \mathrm{~mm})$, the Tp of special point along width and depth of molten are shown in Figure 17, from Figure 17, each group including three bars, represented three different welding speed (i.e., different heat input) of 60,80, 100 $\mathrm{cm} / \mathrm{min}$. Obviously, under the same spacing with the increase of welding speed, the values of Tp gradually reduce; in the same heat input (i.e., the same welding speed), with the increase of the double wire spacing, the values of $\mathrm{Tp}$ is decline; Among them, from the line 1, expressing with the different welding speed, the change trend of Tp of surface point $(0,2,0)$ is shown, while line 3 , the change trend of another point $(0,8,0)$ is shown; from line 2, at the same welding speed of $60 \mathrm{~cm} / \mathrm{min}$, the change trend of $\mathrm{Tp}$ of point $(0,2,0)$ is shown; according to slope of line 1,2 , we can find that the influence of the welding heat input $\mathrm{E}$ is greater than that of double wire distance $\mathrm{L}$, according the slope of the line 1,3, it is known that the welding heat input $\mathrm{E}$ is greater influence on $\mathrm{Tp}$ as the points closer to heat source center; the value of $\mathrm{E}$ is the most sensitive factor on the Tp. Along the direction of the width and depth of molten pool and farther away from heat center, with the widening of double wire spacing and the increase of welding speed, the $\mathrm{Tp}$ is decreased. 


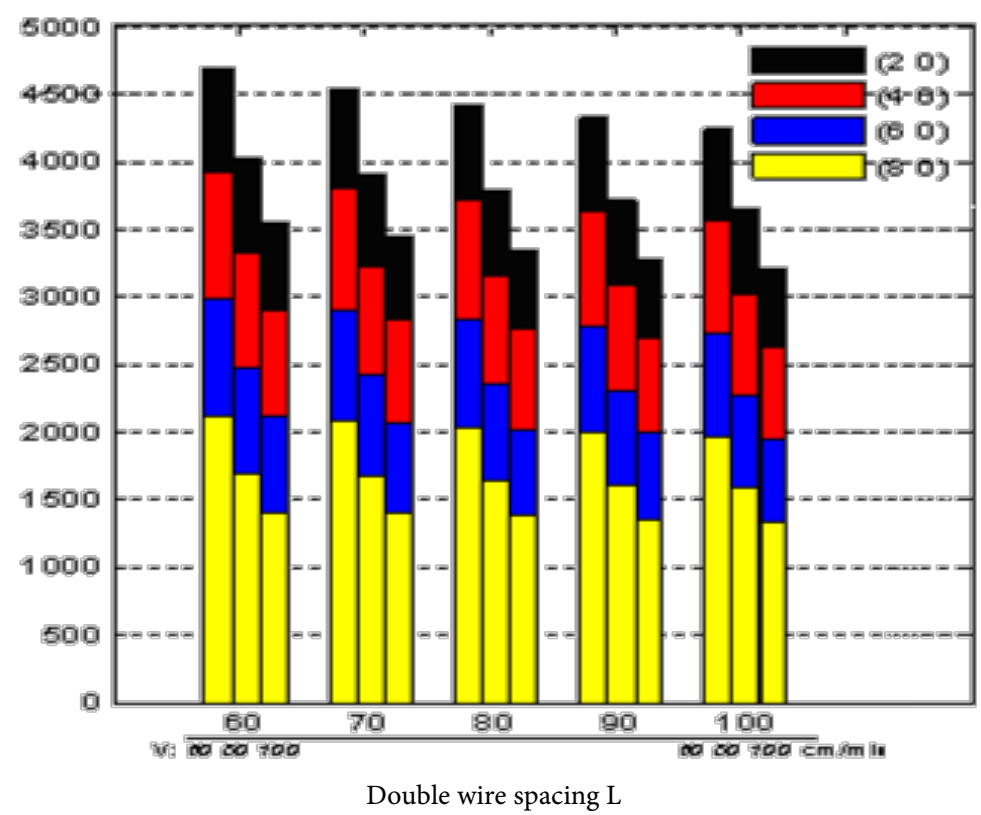

(a)

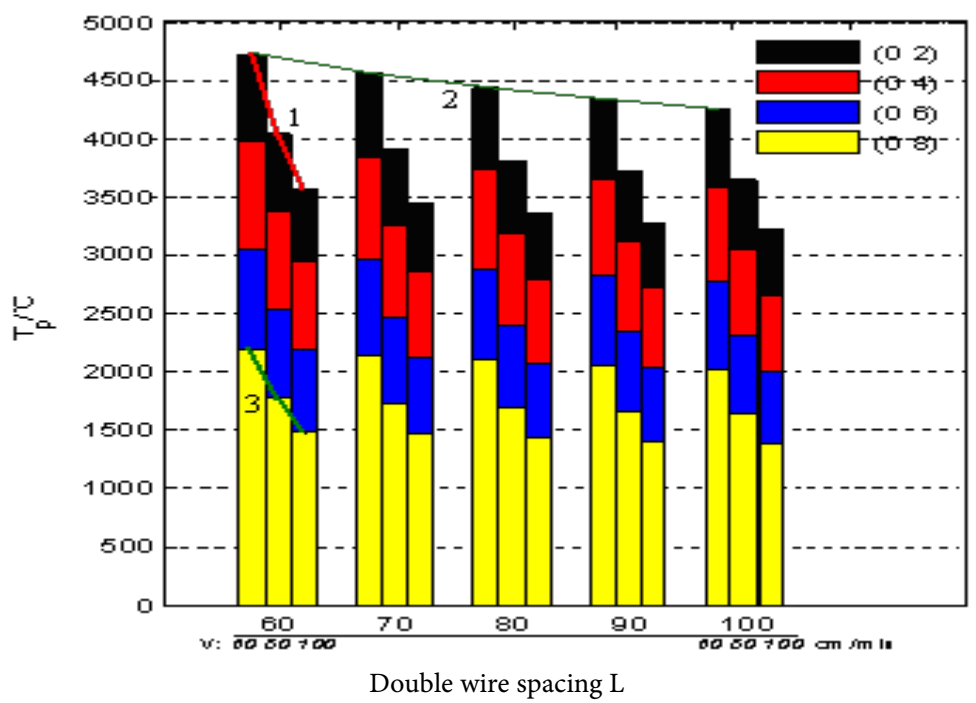

(b)

Figure 17. Histogram of Tp. (a) Tp of direction depth of molten; (b) Tp of direction of width.

\subsubsection{The Tp under the Different Heat Input $\mathrm{E}$}

With double wire spacing $\mathrm{L}(50 \mathrm{~mm})$, along penetration direction, the variation of $\mathrm{Tp}$ to heat input $\mathrm{E}$ is shown in Figure 18. The proportion of $\mathrm{E}_{1}$ to $\mathrm{E}_{2}$ could be found in Figure 8: covered several sets (such as 1, 3, 9, 13) of E1 < E2 and the other sets of E1 > $\mathrm{E} 2$. We can see that the $\mathrm{Tp}$ is not always rising with the increasing of the heat input $\mathrm{E}$, $\mathrm{Tp}$ is more closely related to E1 than to E2.

From the Figure 18, to the values of $\mathrm{Tp}$, it is can been seen that double wire spacing $(\mathrm{L})$ is much less than that of the heat input $\mathrm{E}$. In one word, double wire spacing has less influence on $\mathrm{Tp}$, heat input (E) is the main factor on $\mathrm{Tp}$, the heat input $\mathrm{E}_{1}$ is the more 


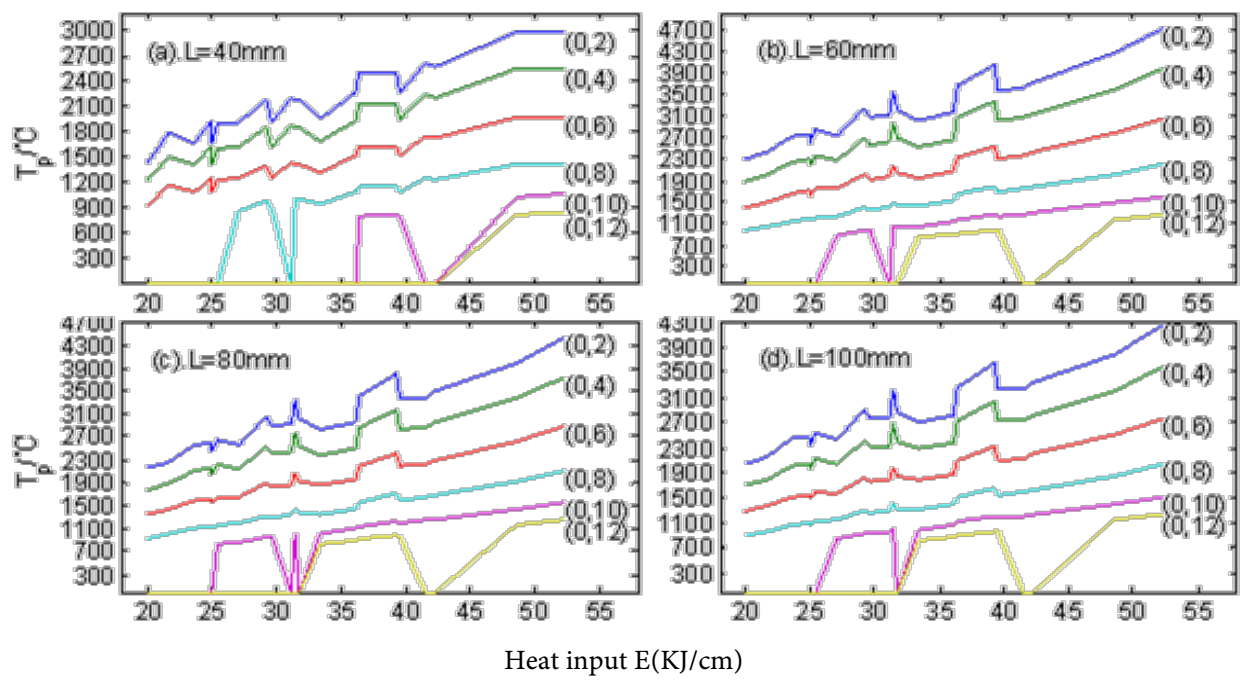

Figure 18. The curve of Tp with $\mathrm{E}$ under the different spacing.

sensitive factor than $\mathrm{E}_{2}$.

\section{Conclusions}

(1) Along the points of further from the center of the heat source, the peak temperature (Tp) is lower, the $t_{8 / 5}$ constantly is increasing. while the double wire spacing $\mathrm{L}$ only have affect on the peak temperature (Tp), almost less affect $t_{8 / 5}$. Therefore, it is effective method by the mean of increasing the double wire spacing $(\mathrm{L})$ to reduce the peak temperature (Tp) without changing the $t_{8 / 5}$. On the one hand, we can prevent microstructure of HAZ from burnt, on the other hand, we can guarantee the microstructure transformation of weld fusion line by control cooling process.

(2) By the secondary development of ANSYS, the thermal field of double wire welding was simulated, the part laws of thermal cycle of double wire welding was found. We can improve the microstructure and mechanical properties by the way of adjusting weld process parameters.

\section{Acknowledgements}

This work was partly supported by the "Hubei Province Education Department youth project (No.Q20123001). Hubei province natural science foundation of China (No.2014 CFB 177), Dr. Field introduced project (No.11yjz01R), Field introduced project (2015A05)".

\section{References}

[1] Yang, X.Z., Tang, Z.M., Yu, S.F., et al. (2010) About the Calculation of Double Wire Welding Temperature Field of Improvement Algorithm Program Design. Journal of Welding, 53-56.

[2] Yang, X.Z., Yu, S.F., Yao, R.G., et al. (2010) Double Moving Heat Source of Heat Flow Value of Efficiency Calculation and Load. Journal of the Hua Zhong University of Science 
and Technology, 101-104.

[3] Mo, C.L., Qian, B.N., Guo, X.M., et al. (2001) The Research Progress of Welding Heat Source Computing Model. Journal of Welding, 6, 94-97.

[4] Zhao, P.C., Wu, C.S. and Zhang, Y.M. (2004) Numerical Simulation of the Dynamic Characteristic of Weld Pool Geometry with Step Changes of Welding Parameters. Modeling and Simulation in Materials Science and Engineering, 765-780.

[5] Wu, C.S., Chen, J. and Zhang, Y.M. (2007) Numerical Analysis of Both Front- and Back-Side Deformation of Fully-Penetrated GTAW Weld Pool Surfaces. Computational Materials Science, 4, 635-642.

[6] Turna, M., Taraba, B., Ambroz, P., et al. (2011) Contribution to Numerical Simulation of Laser Welding. Physics Procedia, 12, 638-645.

[7] Ranjbarnodeh, E., Kokabi A.H. and Fischer, A. (2011) Effect of Welding Parameters on Residual Stresses in Dissimilar Joint of Stainless Steel to Carbon Steel. Journal of Materials Science, 46, 3225-3232.

[8] Eagar, B.W. and Tsai, N.S. (2012) Temperature Fields Produced by Traveling Distributed Heat Sources. Welding Research Supplement.

\section{Submit or recommend next manuscript to SCIRP and we will provide best service for you:}

Accepting pre-submission inquiries through Email, Facebook, LinkedIn, Twitter, etc. A wide selection of journals (inclusive of 9 subjects, more than 200 journals)

Providing 24-hour high-quality service

User-friendly online submission system

Fair and swift peer-review system

Efficient typesetting and proofreading procedure

Display of the result of downloads and visits, as well as the number of cited articles

Maximum dissemination of your research work

Submit your manuscript at: http://papersubmission.scirp.org/

Or contact msce@scirp.org 